\title{
Review of Different Methods Used for Confirmation of Endotracheal Tube Placement in Newborns
}

\section{RamaaVijaykumar and Ashwin R Saboo*}

Al Corniche Hospital, Abu Dhabi, Abu Dhabi, UAE

*Corresponding author:Ashwin R Saboo, Department of Neonatology, Al Corniche Hospital, Corniche Road, Abu Dhabi 3788, UAE, Tel: +971551279804; E-mail: ashwinrsaboo@gmail.com

Rec date:Apr 14, 2014; Acc date: July 28, 2014; Pub date: August 02, 2014

Copyright: (C) 2014 Vijaykumar R et al., This is an open-access article distributed under the terms of the Creative Commons Attribution License, which permits unrestricted use, distribution, and reproduction in any medium, provided the original author and source are credited.

\begin{abstract}
Endotracheal intubation forms an indispensable component of neonatal resuscitation. Due to very small tracheal length and other anatomical constraints, placement of Endotracheal Tube (ETT) accurately in a neonate has always been a difficult task. Despite various recent advances in neonatology, significant proportions of intubations are still inappropriately positioned. Malpositioned ETT are more likely to cause complications. These complications may become irreversible quite early in the course, particularly in preterm neonates. In this paper, we aim to elucidate various methods that aid in determining the accurate placement of an ETT in neonates.
\end{abstract}

\section{Introduction}

Birth asphyxia is an important preventable cause of morbidity and mortality especially in the developing countries. In India around 4-6\% babies require some assistance for breathing while worldwide the number ranges from $1-10 \%[1-3]$.

Neonatal intubation was developed on the basis of work by Chevalier Jackson, the American pioneer in bronchoesophagology, who designed a pediatric laryngoscope. Since then, laryngoscope has made endotracheal intubation more universally accessible almost becoming a part of the standard arsenal in the delivery room and Neonatal Intensive Care Unit (NICU) [4]. Due to short tracheal length and several anatomical constraints placement of Endotracheal Tube (ETT) accurately in a neonate has always been a herculian task. There are studies which suggest that ETT is incorrectly positioned in $>50 \%$ of the cases $[2,5,6]$.Incorrect placement of ETT may lead to serious problems like hypoxemia, pneumothorax, unilateral ventilation etc. [2,5]. Manual ventilation with a few large breaths at birth may cause lung injury and blunt the effect of subsequent surfactant treatment. The immature lung may be particularly vulnerable at birth not only because it lacks surfactant but also because it is fluid-filled with little room for air entry [7]. Various methods that aid in determining the accurate placement of an ETT have been described. Through this article we aim to review those methods.

\section{Clinical Signs}

For ages clinical signs have been in use and have helped to a great extent in predicting accurate placement of the tube. International guidelines also recommend the use of both clinical signs as well as capnography for determining exact placement of ETT [2]. Clinical signs that indicate correct intratracheal ETT placement include a prompt increase in heart rate, chest wall movement, presence of bilaterally equal breath sounds on auscultation, absence of breath sounds in the epigastrium and condensation in the ETT during expiration $[8,9]$.Apart from the above mentioned clinical signs; direct visualisation of the tube passing through vocal cords serve as an important marker for accurate placement. This is further ensured by placing the vocal cord guide or the black line on the ETT exactly at the level of vocal cords. Though this technique minimises the chances of endobronchial intubation it is not a foolproof method as the position of the vocal cord guide vary amongst different manufacturers [10].

There are many advantages of using clinical signs to confirm ETT placement like it can be done bedside, can be easily taught and can be followed universally as it doesn't demand any intricate technology. Despite this there is an evidence to show that many of these clinical signs may not be capable of assessing the exact depth of insertion sometimes even leading to endobronchial intubation [11].

\section{Capnography}

Capnography is the method of detection of exhaled $\mathrm{CO}_{2}$ i.e. end tidal $\mathrm{CO}_{2}$ using colorimeter and is proven to be quite effective for confirmation of presence of ETT in trachea. Current international guidelines recommend its use along with clinical signs for neonatal intubation $[2,12]$ When used in combination with clinical signs it reduces the amount of time required to correctly position the ETT $[12,13]$. Capnometers are disposable semi-quantitative colorimetric detectors with an incorporated $\mathrm{pH}$ sensitive chemical indicator. This undergoes a color change on inflation and expiration (e.g. from purple to yellow), indirectly reflecting the change in $\mathrm{CO}_{2}$ concentration in the gas passing through it. A positive test result confirms placement of the ETT within the trachea, whereas a negative test result strongly suggests oesophageal intubation. Very rarely a false positive test can be obtained with oesophageal intubation. This can be easily picked up as $\mathrm{CO}_{2}$ concentration in such cases starts falling rapidly after a few breaths unlike tracheal intubation [14,15]. There are newer capnographic devices now available which quantitatively detect the exhaled $\mathrm{CO}_{2}$ using infrared light.

There are different techniques to measure the end tidal $\mathrm{CO}_{2}$ in neonates using capnography. One is a mainstream capnometry wherein the capnometer is in-line with the ventilatory circuit while others are side stream capnometry and micro stream technique which are mainly used to measure the distal end tidal $\mathrm{CO}_{2}$. A study was conducted by Kugelman et al. who compared arterial $\mathrm{CO}_{2}$ values to 
that of proximal and distal end tidal $\mathrm{CO}_{2}$ obtained using capnometry in the intubated neonates. The results of the study showed that the values of mean pulmonary arterial $\mathrm{CO}_{2}$, distal end tidal $\mathrm{CO}_{2}$ and proximal end tidal $\mathrm{CO}_{2}$ were 46.3 (24.5-99.7) 46 (20-98) and 37 (1271) $\mathrm{mmHg}$ respectively. The study thus concluded that distal end tidal $\mathrm{CO}_{2}$ co-related better with arterial $\mathrm{CO}_{2}$ especially when the arterial $\mathrm{CO}_{2}$ values were more than $60 \mathrm{mmHg}$ [16].

Mentioned below are the two conditions where capnography may prove to be of limited value.

1) Conditions affecting cardiac output often lead to decreased pulmonary blood flow further leading to low $\mathrm{CO}_{2}$ concentration in the blood. As capnometer mainly relies on partial pressure of $\mathrm{CO}_{2}$ in blood it may not give accurate results in such cases despite accurate placement of ETT. Hence in patients with low cardiac output like very sick newborns or complicated heart disease capnometer may not be that reliable [13].

2) The success of this technique largely depends upon the tidal volume threshold of a newborn. The minimum tidal volume required for detection that is $0.83 \mathrm{ml}-1.08 \mathrm{ml}$ is normally generated by almost any viable newborn. In extremely premature newborns who are ventilated the positive pressure used for ventilation may fail to generate the required tidal volume thus giving rise to false negative results on capnography $[13,17]$.

Thus to summarise capnography is indeed a very quick and reliable method for indicating tracheal presence of ETT but is ineffective in presence of low cardiac output and also fails to ascertain the exact depth of the ETT insertion $[5,6,9]$.

\section{Chest X Ray (CXR)}

CXR is one of the ancient and most frequently used methods for confirming the ETT placement and is often considered gold standard in assessing the exact location of ETT.Different landmarks were used in different studies to indicate exact location of ETT.One of the studies observed that tracheal midpoint corresponded internally to a line drawn between the medial heads of the clavicles and thus used clavicles as the reference point $[1,5,18,19]$ However Blayney et al. found the position of the clavicle on CXR to be inconsistent and suggested use of first thoracic vertebra as a marker for correct tip placement [20]. The take home point is irrespective of the reference point used tube must always be positioned at a safe distance from the carina in order to avoid accidental endobronchial intubation.

To conclude though confirmation of ETT using CXR may be regarded as highly accurate it is less likely to be available instantaneously. This can be considered as one of the major disadvantage especially when interventions like surfactant administration etc. are planned.

\section{Estimation of depth of ETT insertion based on formulae}

The placement of ETT at an exact depth is of paramount importance and clinical signs or capnography both are grossly incapable of predicting the same. Though clinical signs may provide us with a valuable input about tracheal placement of tube it doesn't throw much light on the depth of placement. Harris et al studied the incidence of malposition of ETT when only clinical signs were considered and he concluded that it was as high as $35 \%$ in infants.
Similarly capnography also fails to give an exact idea about the depth of ETT $[15,21,22]$.

Several formulae have been proposed to calculate the correct ETT placement within the trachea $[2,23,24]$ However they are often cumbersome to use during emergencies and are more likely to be error prone. In 1979 Tochen devised a new formula to determine insertional length while intubating through orotracheal route. He proposed that "tip-to-lip" distance can be used to determine the depth of placement which is also popularly known as rule of 7-8-9.Despite being easy-touse the 7-8-9 rule appears to inaccurately position the ETT in infants weighing $<750 \mathrm{~g}$ thus restricting their use to relatively good weight babies $[1,5]$. Several studies re-examined Tochen's rule and reported that the depth predicted by this rule assumes a linear relationship with body length but a non-linear one with the body weight. One such study conducted by Amrilyo et al concluded that Tochen's rule when used alone in babies weighing less than $1000 \mathrm{~g}$ led to inaccurate placements in more than $47 \%$. Thus they reinforced using clinical signs especially auscultation in addition to this rule [13]. The study done by Kempley et al also stressed on the fact that Tochen's rule when used in babies below $1 \mathrm{~kg}$ led to erroneous intubation of right stem bronchus and considered it to be unfavourable for neonates of smaller gestational age [25]. Another flipside suffered by this method is that it cannot be applied for nasotracheal intubation.

\section{External Digital Tracheal Palpation}

In 1975 Bednarek and Kuhns first reported a simple technique to confirm ETT position using digital suprasternal palpation on neonates after which randomised control trials were conducted and this technique was further evaluated by Jain et al and Saboo et al. $[5,18,26]$. In this technique, ETT tip is palpated as it passes beneath the palpating finger placed in the suprasternal notch.(Figure 1)Jain et al. carried out a Randomized Control Trial (RCT) comparing suprasternal palpation, with standard chest radiography to reassess the potential benefit of ETT palpation technique in neonates [26]. They concluded that palpation had a placement prediction accuracy of $70 \% \quad(n=38)$ compared to CXR (the gold standard). Going further they proposed that palpation done by experienced personnel was useful where CXR was not immediately available, but cannot substitute CXR. Prediction of correct ETT position, as well as prediction of initial ETT position (i.e. both correct and suboptimal positions) by palpation and CXR were compared and found to be significantly different. Saboo et al. recently showed that, with trained hands, palpation method is at least as accurate as 7-8-9 rule, if not more [5]. They showed it to be a simple, safe, teachable, method of confirming ETT position in neonates when CXR is unavailable. The most important advantage of this method is that it can be applied at the point of care, during emergencies without any requirement of any sophisticated equipment. It also helps accurately position the ETT at the required depth within trachea.

\section{Ultrasound}

In 1986 Slovis et al. demonstrated that real-time Ultrasound (US) could be used to verify correct ETT position in newborn infants. According to the author US must be performed by a trained personnel, using 5-8 MHz probe and ETT tip must lie somewhere between $0.5 \mathrm{~cm}$ to $1.0 \mathrm{~cm}$ from upper border of arch of aorta [22]. Advantages of ultrasonography over $\mathrm{X}$ ray include: (i) absence of radiation, (ii) less handling, particularly in critically ill infants, (iii) potential to determine the ETT position in the delivery room particularly for early 
surfactant delivery and (iv) early detection of complications from malposition. Disadvantages of ultrasonography are (i) requirement of specialized skills and trained personnel (ii) difficulties to correctly identify anatomical landmarks and (iii) lack of widespread availability $[21,22]$.

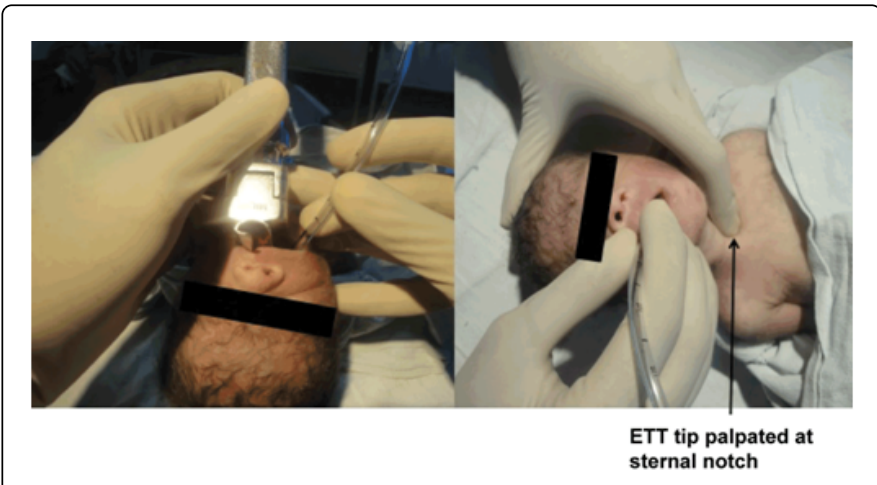

Figure 1:Suprasternal digital palpation method. ${ }^{*}$ ETT Endotracheal Tube.

\section{Respiratory function monitor}

Inability of capnography to detect accurate position of ETT in premature and sick neonates led to the advent of respiratory function monitor which successfully overcame these shortcomings. John Robinson first described the use of airway pressure and gas flow waves to identify correct ETT placement.The machinery consists of a flow sensor placed between the ETT and the ventilation device which translates the gas flow into flow waves which is then read by an observer. If the gas flow is observed in both the directions that is inspiratory as well as expiratory it can be concluded that ETT is in the trachea while on the contrary if inspiratory gas flow alone is detected it may be assumed that tube is in the oesophagus $[8,27]$. Schmolzer et al. conducted a study in preterm infants wherein they compared the accuracy of respiratory flow sensors with that of capnography in determining the placement of ETT [27]. The results showed that capnography failed to detect ETT in more than one third of babies especially the ones who were ventilated and the ones who suffering from severe cardiac disease as its accuracy was heavily dependent on the inflating pressures provided during ventilation and cardiac output of the newborn respectively [8].

Flow sensors thus seem to supersede capnography in many ways as they are less likely to get affected by cardiac output of the newborn and inflating pressure of the ventilator. The demerits suffered by this novel technique however are requirement of experienced personnel for interpretation of the flow signals and inability to judge the exact depth of the ETT [27].

\section{Videolaryngoscope}

Usage of videolaryngoscope in the paediatrics was first reported by Weiss. In general the device contains a fibre-optic light bundle incorporated in the laryngoscope blade which illuminates the passage without interfering in the process of intubation and the whole passage is magnified and can be viewed on a large screen with the help of a camera attached to the apparatus [4,28]. Recently John et al conducted a randomisedcontrol trial comparing the intubation times between
Glidescope Cobalt videolaryngoscope and direct laryngoscope in neonates and infants and concluded that the intubation time with both the procedures remained the same. They found that with videolaryngoscope the glottic view was better as well as faster; however the time taken for the passage of tube was longer as it required technical expertise and good hand- eye co-ordination [29].

This newer method is slowly gaining popularity amongst the intensivists as it provides improved visibility for the operator and assistants, expanded opportunity for supervision and teaching, and helps in recording and archiving for documentation and consultation purposes. However technical expertise needed to use these instruments and reduced availability of such infrastructure combined with high cost makes this a lesser used technique amongst the clinicians $[4,28,29]$.

\section{Fiber Optic Devices}

The fiber optic laryngoscope/bronchoscope for endotracheal intubation was first described by Stiles in 1972. These devices emit light and are ultrathin and are thus easy to manoeuvre and can accurately determine the exact depth of insertion of ETT $[28,30]$. Recently J Kaufmann et al. conducted a RCT comparing videolaryngoscope and fiberoptic bronchoscope in small infants and children [31]. It was observed that though visualisation of glottic area with videolaryngoscope was good it was very difficult to manoeuvre the tube through it because of its sharp angled blade and increased width of the tip.Ascomparated to them fiberoptic scopes are thin with in- built optical system and they provide a full view of the whole oral passage and help us easily circumnavigate any obstacles. Thus it was observed that time taken for intubation was much lesser with fibreoptics as compared to videolaryngoscope [31]. It is very reliable in newborns of all gestational ages and weights and particularly very helpful in those with difficult airway and ones with decreased pulmonary blood flow. Apart from this it can serve as a very convenient method when one needs to perform interventions like instillation of surfactant, one lung ventilation, removal of a mucous plug etc. [30,31].

The demerits suffered by this method are longer time required to visualize the vocal cords, special training required to operate the flexible fiberscope efficiently in emergency settings and limited availability of the instruments and expertise.

\section{Conclusions}

Neonatal intubation warrants quick and accurate ETT insertion and embodies timely ascertainment of its position. CXR remains the gold standard to confirm ETT position, against which other methods are compared. Direct visualization of ETT tip passing through the cords is the most reliable clinical sign ensuring intratracheal placement followed by improvement in heart rate. Palpating the ETT tip at the suprasternal notch is the only clinical method to gauge the depth of insertion but more trials are required before any recommendation be made. Neonatal videolaryngoscopic intubation presents an expanded opportunity for supervising, teaching, and recording the procedure but their efficient use requires more training.

We strongly recommend use of one or more methods for estimation of position of ETT in a neonate as it may help in decreasing the margin of error significantly. In a resource limited setting one can combine different methods such as direct visualisation of passage of ETT through vocal cords under laryngoscopic guidance followed by 
auscultation of breath sounds bilaterally and observation of mist production in the tube during expiration while judging the placement of the tube. In places where capnometer is available $\mathrm{ETCO}_{2}$ can play a pivotal role in estimating the accuracy of placement of the tube.As far as exact depth of insertion is considered one can first deduce the exact length of ETT to be inserted using one of the formulae and couple it with digital palpation of the ETT tip at suprasternal notch. The placement of vocal cord guide at the level of vocal cords may additionally help in accurate estimation of the depth. However one has to fall back on CXR or US for confirmation. In settings where infrastructure and expertise are not an issue one can directly use respiratory function monitors and videolaryngoscope for establishing the exact placement but they may also be required to be coupled with clinical signs or US for further confirmation. Fibre optic devices by and large would obviate the need for multiple methods and can be solely used in future to detect the exact placement of ETT in almost all cases. Thus there is a possibility that multiple methods used in combination might be more accurate, but the data for it is still lacking. In future, as more data would be generated, the recommendations for neonatal intubation may undergo rapid evolution.

\section{References}

1. Peterson J, Johnson N, Deakins K, Wilson-Costello D, Jelovsek JE, et al. (2006) Accuracy of the 7-8-9 Rule for endotracheal tube placement in the neonate. J Perinatol 26: 333-336.

2. Kattwinkel J, Perlman JM, Aziz K, Colby C, Fairchild K, Gallagher J, et al. (2010) Neonatal resuscitation: 2010 American Heart Association Guidelines for Cardiopulmonary Resuscitation and Emergency Cardiovascular Care. Circulation 122:S909-919.

3. Deorari AK, Paul VK, Singh M, Vidyasagar D (2000) The National Movement of Neonatal Resuscitation in India. J Trop Pediatr 46: 315-317.

4. Vanderhal AL, Berci G, Simmons CF Jr, Hagiike M (2009) A videolaryngoscopy technique for the intubation of the newborn: preliminary report. Pediatrics 124: e339-346.

5. Saboo AR, Dutta S, Sodhi KS (2013) Digital palpation of endotracheal tube tip as a method of confirming endotracheal tube position in neonates: an open-label, three-armed randomized controlled trial. PaediatrAnaesth 23: 934-939.

6. O'Donnell CP,Kamlin CO, Davis PG, Morley CJ (2006) Endotracheal intubation attempts during neonatal resuscitation: success rates, duration, and adverse effects. Pediatrics 117:e16-21.

7. Ingimarsson J, Björklund LJ, Curstedt T, Gudmundsson S, Larsson A, et al. (2004) Incomplete protection by prophylactic surfactant against the adverse effects of large lung inflations at birth in immature lambs. Intensive Care Med 30: 1446-1453.

8. Schmölzer GM, O'Reilly M, Davis PG, Cheung PY, Roehr CC (2013) Confirmation of correct tracheal tube placement in newborn infants. Resuscitation 84: 731-737.

9. Yam CH, Dawson JA, Schmölzer GM, Morley CJ, Davis PG (2011) Heart rate changes during resuscitation of newly born infants $<30$ weeks gestation: an observational study. Arch Dis Child Fetal Neonatal Ed 96: F102-107.

10. Gill I, O'Donnell CP (2014) Vocal cord guides on neonatal endotracheal tubes. Arch Dis Child Fetal Neonatal Ed .

11. Mainie P, Carmichael A, McCullough S, Kempley ST (2006) Endotracheal tube position in neonates requiring emergency interhospital transfer. Am J Perinatol 23: 121-124.

12. Leone TA, Rich W, Finer NN (2006) A survey of delivery room resuscitation practices in the United States. Pediatrics 117: e164-175.
13. Repetto JE, Donohue PA-C PK, Baker SF, Kelly L, Nogee LM (2001) Use of capnography in the delivery room for assessment of endotracheal tube placement. J Perinatol 21: 284-287.

14. Garey DM, Ward R, Rich W, Heldt G, Leone T, et al. (2008) Tidal volume threshold for colorimetric carbon dioxide detectors available for use in neonates. Pediatrics 121: e1524-1527.

15. Harris EA, Arheart KL, Penning DH (2008) Endotracheal tube malposition within the pediatric population: a common event despite clinical evidence of correct placement. Can J Anaesth 55: 685-690.

16. Kugelman A, Zeiger-Aginsky D, Bader D, Shoris I, Riskin A (2008) A novel method of distal end-tidal $\mathrm{CO} 2$ capnography in intubated infants: comparison with arterial $\mathrm{CO} 2$ and with proximal mainstream end-tidal CO2. Pediatrics 122: e1219-1224.

17. Aziz HF, Martin JB, Moore JJ (1999) The pediatric disposable end-tidal carbon dioxide detector role in endotracheal intubation in newborns. J Perinatol 19: 110-113.

18. Bednarek FJ, Kuhns LR (1975) Endotracheal tube placement in infants determined by suprasternal palpation: a new technique. Pediatrics 56: 224-229.

19. Amarilyo G, Mimouni FB, Oren A, Tsyrkin S, Mandel D (2009) Orotracheal tube insertion in extremely low birth weight infants. J Pediatr 154: 764-765.

20. Blayney MP, Logan DR (1994) First thoracic vertebral body as reference for endotracheal tube placement. Arch Dis Child Fetal Neonatal Ed 71: F32-35.

21. Sethi A, Nimbalkar A, Patel D, Kungwani A, Nimbalkar S (2014) Point of care ultrasonography for position of tip of endotracheal tube in neonates. Indian Pediatr 51: 119-121.

22. Galicinao J, Bush AJ, Godambe SA (2007) Use of bedside ultrasonography for endotracheal tube placement in pediatric patients: a feasibility study. Pediatrics 120: 1297-1303.

23. Lau N, Playfor SD, Rashid A, Dhanarass M (2006) New formulae for predicting tracheal tube length. PaediatrAnaesth 16: 1238-1243.

24. Rotschild A, Chitayat D, Puterman ML, Phang MS, Ling E, et al. (1991) Optimal positioning of endotracheal tubes for ventilation of preterm infants. Am J Dis Child 145: 1007-1012.

25. Kempley ST, Moreiras JW, Petrone FL (2008) Endotracheal tube length for neonatal intubation. Resuscitation 77: 369-373.

26. Jain A, Finer NN, Hilton S, Rich W (2004) A randomized trial of suprasternal palpation to determine endotracheal tube position in neonates. Resuscitation 60: 297-302.

27. Schmölzer GM, Poulton DA, Dawson JA, Kamlin CO, Morley CJ, et al. (2011) Assessment of flow waves and colorimetric CO2 detector for endotracheal tube placement during neonatal resuscitation. Resuscitation 82: 307-312.

28. Birmingham PK, Cheney FW, Ward RJ (1986) Esophageal intubation: a review of detection techniques. AnesthAnalg 65: 886-891.

29. Fiadjoe JE, Gurnaney H, Dalesio N, Sussman E, Zhao H, et al. (2012) A prospective randomized equivalence trial of the GlideScope Cobalt(R) video laryngoscope to traditional direct laryngoscopy in neonates and infants. Anesthesiology 116:622-628.

30. Vigneswaran R, Whitfield JM (1981) The use of a new ultra-thin fiberoptic bronchoscope to determine endotracheal tube position in the sick newborn infant. Chest 80: 174-177.

31. Kaufmann J, Laschat M, Hellmich M, Wappler F (2013) A randomized controlled comparison of the Bonfils fiberscope and the GlideScope Cobalt AVL video laryngoscope for visualization of the larynx and intubation of the trachea in infants and small children with normal airways. PaediatrAnaesth:913-919. 